\author{
Original
}

\title{
Vision-aided system for obtaining a required weight by efficient choice of irregular fragments
}

\author{
Francisco Sánchez Niño ${ }^{\mathrm{a}, *}$, Victor Hugo Compeán Jasso ${ }^{\mathrm{b}}$, Francisco Javier De Anda Salazar ${ }^{\mathrm{a}}$, \\ Carlos Soubervielle Montalvo ${ }^{\mathrm{c}}$, Juan Carlos Muñoz ${ }^{\mathrm{c}}$ \\ a Instituto de Investigación en Comunicación Óptica IICO-UASLP, San Luis Potosí, Mexico \\ ${ }^{\mathrm{b}}$ CONACYT Research Fellow - Instituto de Investigación en Comunicación Óptica IICO-UASLP, San Luis Potosí, Mexico \\ ${ }^{\mathrm{c}}$ Facultad de Ingeniería UASLP, San Luis Potosí, Mexico
}

Received 27 June 2016; accepted 23 January 2017

Available online 15 March 2017

\begin{abstract}
There are some situations when it is necessary to weigh, with high accuracy and high precision, a required amount of material using heterogeneous and irregular pieces. As an example, in the laboratory, when preparing a liquid phase epitaxial growth, each of the materials that constitute the liquid phase must have an exact weight, within micrograms, given by the phase diagrams. The sources of the materials usually are small polycrystalline pieces of irregular shapes and random weights. Normally the weighing is done by interchanging the small irregular pieces of different sizes according to the criteria of the operator until the given weight is obtained. This is a long and tedious process and since each liquid solution requires several components, and a different liquid phase is needed for each layer, very often weighing it takes several hours. This operative process is prone to errors. To ease this kind of processes, a vision-assisted system has been developed. It consists of a webcam, an analytical balance and a PC. To use this assembly the operator only needs to put sequentially the pieces of the material in the analytical balance. When the required weight can be obtained by a combination of some of the pieces added to the analytic balance, the PC notifies the operator and signals the selected pieces in the screen. With the help of this system, the weighing accuracy has been improved and the time required to accomplish the process has been dramatically reduced.

(C) 2017 Universidad Nacional Autónoma de México, Centro de Ciencias Aplicadas y Desarrollo Tecnológico. This is an open access article under the CC BY-NC-ND license (http://creativecommons.org/licenses/by-nc-nd/4.0/).
\end{abstract}

Keywords: Arrays; Data acquisition; Data visualization; Image recognition; Machine vision

\section{Introduction}

The exact weighing of a required amount of certain materials can be a frustrating and tedious task if the material is given in irregular pieces of different weights and shapes. Such is the case in the preparation of experiments for the growth of semiconductor heterostructures using the liquid phase epitaxial (LPE) technique (Mishournyi, Hernández, Gorbatchev, \& Lastras, 2002).

In this kind of experiments each layer is grown from a specific multicomponent liquid solution. To prepare the solution with an

\footnotetext{
* Corresponding author.

E-mail address: ninof_sanf@yahoo.com.mx (F.S. Niño)

Peer Review under the responsibility of Universidad Nacional Autónoma de
} México. exact composition, given by the phase diagrams, it is necessary to weigh each component with high accuracy.

A further complication arises because a large number of pieces of each component increases the risk of losing one piece during the following steps of the growth experiment and so the maximum number of pieces allowed of each component of the solution is usually limited to $3-4$.

Normally this process is carried out by an operator that judiciously changes the weighed pieces according to his own experience until the required weight is reached.

Since each liquid solution can have up to five components and normally several liquid solutions are required for one heterostructure, the weighing process can take several hours and thus it is prone to errors committed by the operator.

To facilitate the weighing process, and to reduce the weighing time, a system has been built which consists of an analytic balance, a webcam and a PC (Sánchez Niño, 2009). 


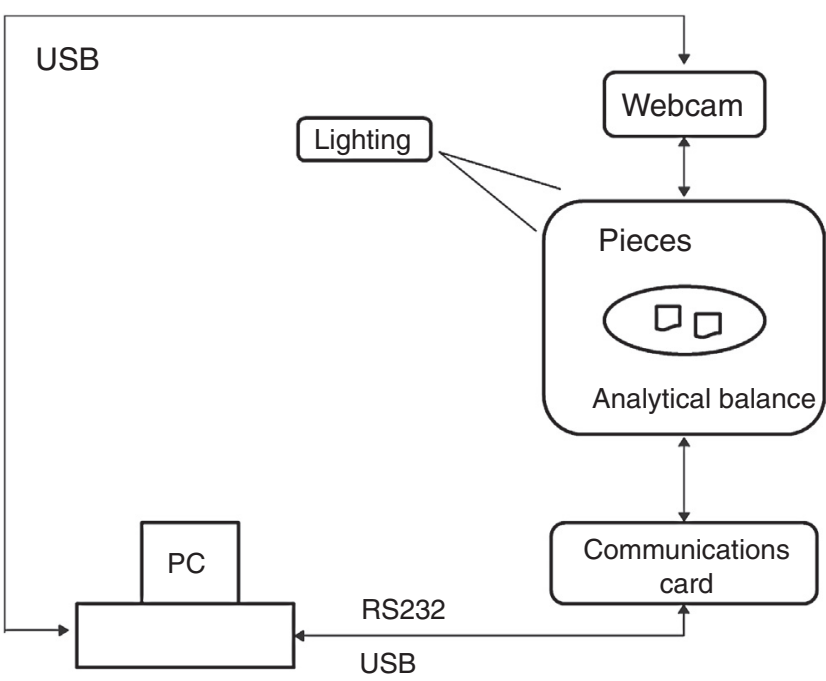

Fig. 1. Block diagram of the weighing system.

To our knowledge there is no report in the literature about any other system built to accomplish this task.

The system works in the following way: when the operator adds a piece to the analytic balance the PC reads its weight and takes a picture using the webcam. The image is processed to label the new piece and register its weight.

Then the PC calculates the weight of each possible combination of the pieces in the analytic balance. If there is a combination of fragments that gives the required amount, the $\mathrm{PC}$ notifies the operator and indicates the pieces on its screen. If the correct weight cannot be achieved with any combination of pieces then the PC asks the operator to add another piece to the analytic balance (Muñoz, 2013).

\section{System design}

Fig. 1 shows a block diagram of the weighing system; it can be divided into three sections as follows:

\subsection{Weight acquisition}

The pieces of the material are weighed in an analytic balance with a resolution of $10 \mu \mathrm{g}$. The PC communicates with the analytic balance through an RS-232 port. A LabVIEW program was written to acquire the weight of each piece. The operator puts a new piece in the analytical balance pan and then clicks a button to start the weighing process, when the analytical balance, previously tared, has determined the piece's weight sends a "ready" signal to the PC which captures the result immediately.

Then the PC sends a command to tare the analytical balance to prepare it to weigh a new piece.

\subsection{Image acquisition and labeling}

When the PC receives the ready signal from the analytical balance, in addition to reading the piece's weight, it sends a signal to the webcam to acquire a photograph. To control the

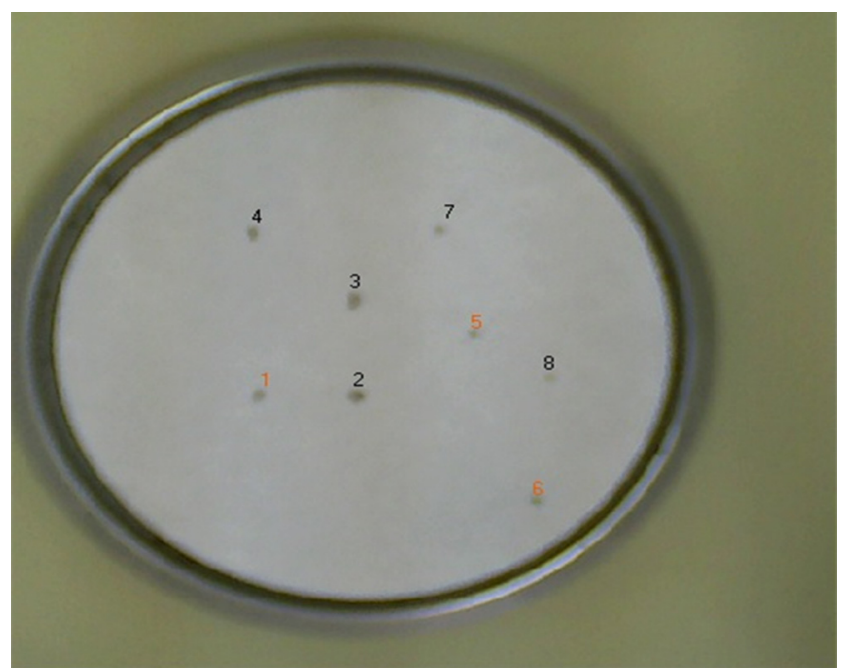

Fig. 2. Example of the output image on the PC screen when the weighing process has succeeded.

webcam and to process the images the LabVIEW IMAQdx tools are used (National Instruments, 2003).

To identify each piece, the photograph containing all the pieces on the analytical balance pan is converted to a binary image and processed to identify each particle. Each piece is then labeled using its location in the image and its weight (National Instruments, 2011a).

\subsection{Data processing}

After a new piece has been weighed and labeled the PC calculates the weight of all the possible combinations of the pieces on the analytical balance pan (National Instruments, 2011b), if one of the combinations has the required weight, within the admissible error, the PC notifies the operator and points to the pieces that form that combination by blinking their images and changing the color of its corresponding number as shown in Fig. 2.

At the beginning of the process the operator defines the admissible error and the maximum number of fragments that can be selected to achieve the required weight.

\section{Results and conclusion}

The system is routinely used to weigh the components of the solutions used in the LPE experiments. The weighing time has been dramatically reduced from several hours to a few minutes.

The weighing time depends mainly on the number of pieces that have to be weighed to obtain the required weight and also on the time the operator takes to put a new piece on the analytical balance pan.

The number of pieces that have to be weighed to obtain the required combination is random, but generally this number increases if the admissible error is reduced and if the maximum number of pieces allowed on a combination is decreased. 
The semi-automated procedure still depends, but to a lesser extent, on the practice of the operator to select the pieces to be weighed.

Also it is necessary to be careful not to put the pieces together touching one another because the image labeling program fails in this case.

The illumination has proved to be very important for the image processing task.

\section{Conflict of interest}

The authors have no conflicts of interest to declare.

\section{Acknowledgments}

This work has been done with partial support from CONACYT and UASLP.

\section{References}

Mishournyi, V. A., Hernández, I. C., Gorbatchev, A. Y., \& Lastras, A. (2002). Tecnologías epitaxiales de crecimiento de cristales semiconductores. Avance y Perspectiva, 21(1), 21-31.

Muñoz, J. C. (2013). Sistema de pesaje de alta precisión para fragmentos irregulares apoyado en procesamiento de imagen. México: Facultad de Ingeniería. Universidad Autónoma de San Luis Potosí (UASLP). Tesis de Maestría.

National Instruments. (2003). IMAQ Vision Concepts Manual. [April 10, 2015], Retrieved from http://www.ni.com/pdf/manuals/322916b.pdf

National Instruments. (2011a). NI Vision Assistant Tutorial, [May 17, 2015]. Retrieved from http://www.ni.com/pdf/manuals/372228m.pdf

National Instruments. (2011b). NI Vision Builder for Automated Inspection Tutorial. [June 12, 2015] Retrieved from http://www.ni.com/ pdf/manuals/373379h.pdf

Sánchez Niño, F. (2009). Automatización del sistema de crecimiento de cristales por epitaxia en fase líquida. México: Facultad de Ciencias. Universidad Autónoma de San Luis Potosí (UASLP). Tesis de Maestría. 